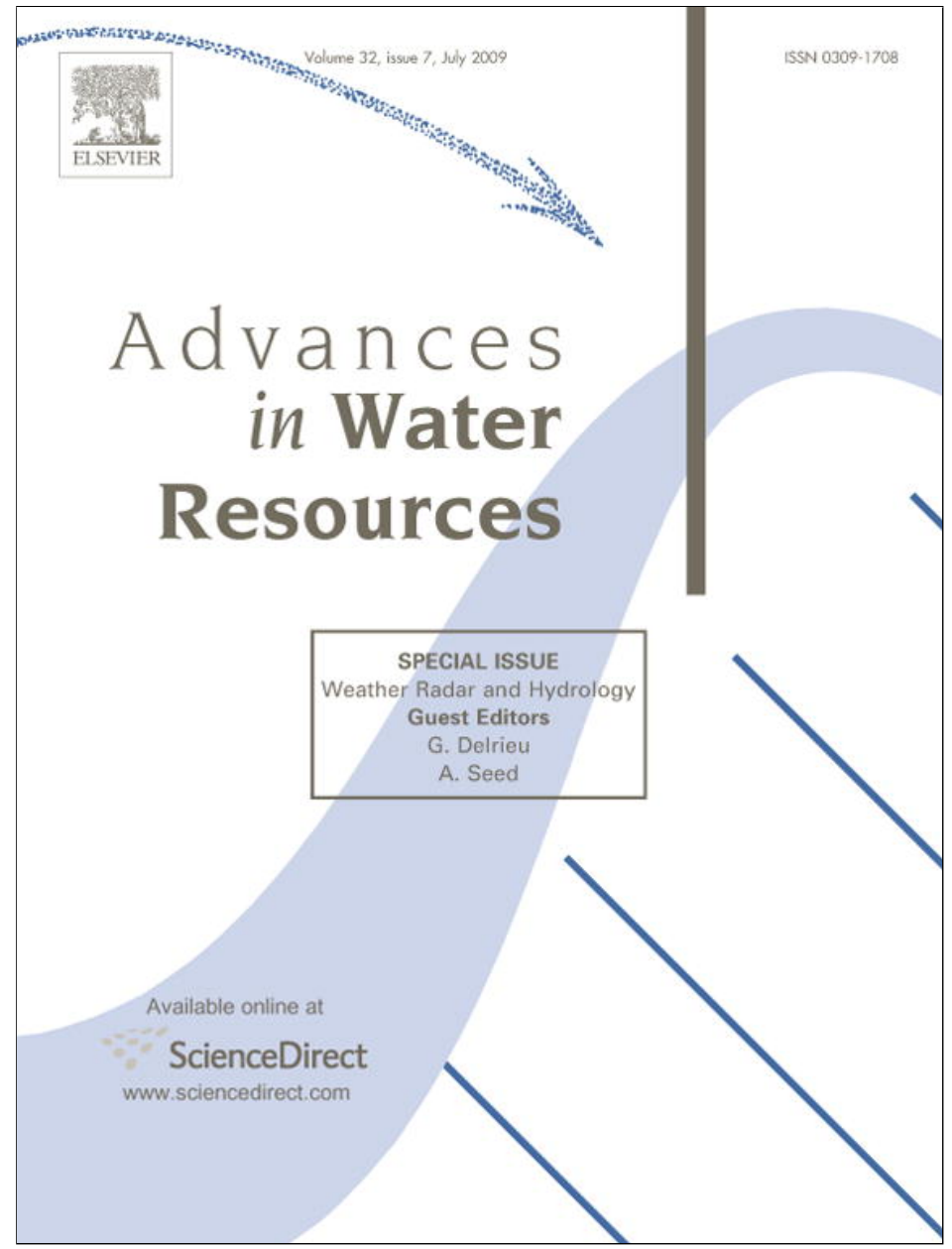

This article appeared in a journal published by Elsevier. The attached copy is furnished to the author for internal non-commercial research and education use, including for instruction at the authors institution and sharing with colleagues.

Other uses, including reproduction and distribution, or selling or licensing copies, or posting to personal, institutional or third party websites are prohibited.

In most cases authors are permitted to post their version of the article (e.g. in Word or Tex form) to their personal website or institutional repository. Authors requiring further information regarding Elsevier's archiving and manuscript policies are encouraged to visit:

http://www.elsevier.com/copyright 


\title{
Variability of the spatial structure of intense Mediterranean precipitation
}

\author{
A. Berne ${ }^{\mathrm{a}, *}, \mathrm{G}$. Delrieu ${ }^{\mathrm{b}}$, B. Boudevillain ${ }^{\mathrm{b}}$ \\ a LTE, École Polytechnique Fédérale de Lausanne, Station 2, 1015 Lausanne, Switzerland \\ ${ }^{\mathrm{b}}$ Laboratoire d'étude des Transferts en Hydrologie et Environnement, Grenoble, France
}

\section{A R T I C L E I N F O}

\section{Article history:}

Received 8 February 2008

Received in revised form 12 November 2008

Accepted 18 November 2008

Available online 3 December 2008

\section{Keywords:}

Precipitation

Structure

Geostatistics

\begin{abstract}
A B S T R A C T
Intense Mediterranean precipitation can generate devastating flash floods. A better understanding of the spatial structure of intense rainfall is critical to better identify catchments that will produce strong hydrological responses. We focus on two intense Mediterranean rain events of different types that occured in 2002. Radar and rain gauge measurements are combined to have a data set with a high spatial $\left(1 \times 1 \mathrm{~km}^{2}\right)$ and temporal $(5 \mathrm{~min})$ resolution. Two thresholds are determined using the quantiles of the rain rate values, corresponding to the precipitating system at large and to the intense rain cells. A method based on indicator variograms associated with the thresholds is proposed in order to automatically quantify the spatial structure at each time step during the entire rain events. Therefore, its variability within intense rain events can be investigated. The spatial structure is found to be homogeneous over periods that can be related to the dynamics of the events. Moreover, a decreasing time resolution (i.e., increasing accumulation period) of the rain rate data will stretch the spatial structure because of the advection of rain cells by the wind. These quantitative characteristics of the spatial structure of intense Mediterranean rainfall will be useful to improve our understanding of the dynamics of flash floods.
\end{abstract}

(c) 2008 Published by Elsevier Ltd.

\section{Introduction}

Mediterranean coastal regions of France are regularly affected by intense rain events producing several hundreds of $\mathrm{mm}$ of rain in tens of hours. These extreme rainfall amounts lead to sudden and devastating flash floods that cause casualties and huge damage. During the last 20 years, such catastrophic flood events occured in Nîmes in 1988 [1], Vaison-la-Romaine in 1992 [2], Aude in 1999 [3] and Gard in 2002 [4]. The Cévennes-Vivarais region (see Section 2) in particular is prone to intense precipitation and flash floods.

During these intense Mediterranean rain events, the spatial and temporal variability of rainfall has been identified as the main controlling factor of the hydrological response of catchments (e.g. [5,6]). It is therefore of primary importance to quantitatively characterize the variability and the structure of intense Mediterranean precipitation in order to improve the understanding, the modeling and the forecasting of rain events generating flash floods. The structure of precipitation has been a question of interest for many years and extensive work has been and is still carried on this topic (e.g. [7-11]).

In this paper, we use geostatistics to investigate the spatial structure of rainfall. The geostatistical framework has been proved to be suited to rainfall studies (e.g. [12-16]). In particular, geostatistics can be used to quantify the variability of precipitation (e.g. [17-19]). According to ([20] p. 3), geostatistical structural analysis aims at answering the following questions:

\footnotetext{
* Corresponding author.

E-mail address: alexis.berne@epfl.ch (A. Berne).
}

"What does an observation at a point tell us about the values at neighboring points? Can we expect continuity in a mathematical sense, or in a statistical sense, or no continuity at all? What is the signal-to-noise ratio? Are variations similar in all directions or is there anisotropy? Do the data exhibit any spatial trend? Are there characteristic scales and what do they represent? Is the histogram symmetric or skewed?"

All these questions are relevant for rainfall structure analysis, but we will focus on the characteristic scales and the anisotropy of intense Mediterranean precipitation, as well as on their variability during intense rain events. This information is crucial for a better understanding of the hydrological responses of catchments affected by intense rainfall.

The main objectives of the present paper are (1) to implement an automatic technique to quantify the structure of rainfall because of the large data set we use, and (2) to analyze the variability of the structure during a rain event and relate this variability to the dynamics of the event. Section 2 presents the study area and the data set. Section 3 describes the methodology developed to quantify the structure of rainfall and the results are discussed in Section 4. Finally, the conclusions are presented in Section 5.

\section{Study area and data}

The Cévennes-Vivarais region is located on the West bank of the river Rhône and close to the Mediterranean sea in France. It has hence a Mediterranean climate characterized by rainy autumns. 
The topography of the region is rugged with altitudes ranging from sea level to $1700 \mathrm{~m}$ at the top of Mont Lozère. The combination of Mediterranean influence with topography favors the occurence of intense rain events and consequently of devastating flash floods.

The main objective of the Cévennes-Vivarais Mediterranean Hydrometeorological Observatory (the French acronym OHM-CV will be used hereafter) started in 2000, is to improve the understanding and modeling of intense Mediterranean precipitation and its hydrological consequences. OHM-CV is thoroughly described in [4], referred to as D05 hereafter, and we will just list the features that are of interest for the present work. Over a $160 \times 200 \mathrm{~km}^{2}$ region, there is a network of 400 daily and 160 hourly rain gauges. This area is moreover covered by three operational S-band weather radars managed by Météo France.

The rain rate data used in this study has been collected during the Bollène-2002 experiment [Delrieu et al., 2008, submitted to J. Appl. Meteor. Climate]. The volume radar data has been processed for clutter filtering using an algorithm based on the pulse-to-pulse reflectivity variability. Rain classification and vertical profile of reflectivity identification have then been performed prior to the estimation of the reflectivity close to the ground. $Z-R$ relationships conditional on rain types were used for the conversion of reflectivity into rain rate. As a final processing step, a radar/rain gauge merging technique has been implemented to reduce the spatial bias. This was done by calculating the ratios between the event total rain amounts estimated from both the daily and the hourly gauge networks (560 instruments in total) and estimated from the radar. These ratios were then interpolated by Kriging and applied to the radar estimates at finer time resolutions $(5 \mathrm{~min}$ to $1 \mathrm{~h})$. In this way, the rain-rate fields reflect the spatial variability as seen by the radar as well as they are consistent with rain gauge measurements. For the employed merging technique, the radargauge ratios calculated at the event time scale are supposed to be representative of ratios at finer time resolutions. This might not be valid for all time steps during an event, but this assumption has a limited influence on the spatial structure of rainfall fields, the main scope of this work.

In the present paper, we focus on an area of $100 \times 150 \mathrm{~km}^{2}$ within the OHM-CV instrumented region as indicated in Fig. 1. Two intense rain events have been selected in the OHM-CV data base.

The first event lasted $28 \mathrm{~h}$ and occured between 08:00 UTC on the 8th of September 2002 and 12:00 UTC on the 9th of September 2002. In the following, it will be referred to as the 20020908 rain event. This event is described in details in D05 and [Bonnifait et al., 2008, this issue]. It was a mesoscale convective system (MCS) that remained stationary over the region. Analyzing the meteorological features, D05 have identified three phases during this event:

(1) 08-22 UTC 8 September: the MCS formed above the sea and moves inland over the plain regions.

(2) 22 UTC 8 September-04 UTC 9 September: the MCS moved up North to the foothill region.

(3) 04-12 UTC 9 September a cold eastward front progressively swept the MCS out of the area.

The total amounts of rainfall were huge all over the region as shown in Fig. 2. The maximum amount was about $700 \mathrm{~mm}$. The area with amounts larger than $400 \mathrm{~mm}$ is about $1900 \mathrm{~km}^{2}$, and the area with amounts larger than $200 \mathrm{~mm}$ is about $5200 \mathrm{~km}^{2}$. These numbers are consistent with those given in D05. Such rain amounts generated flash floods and catastrophic floodings in the Gard plains.

The second event lasted $18 \mathrm{~h}$ and occured between 06:00 UTC and 24:00 UTC on the 11th of November 2002. In the following, it will be referred to as the 20021124 rain event. This event is typ-
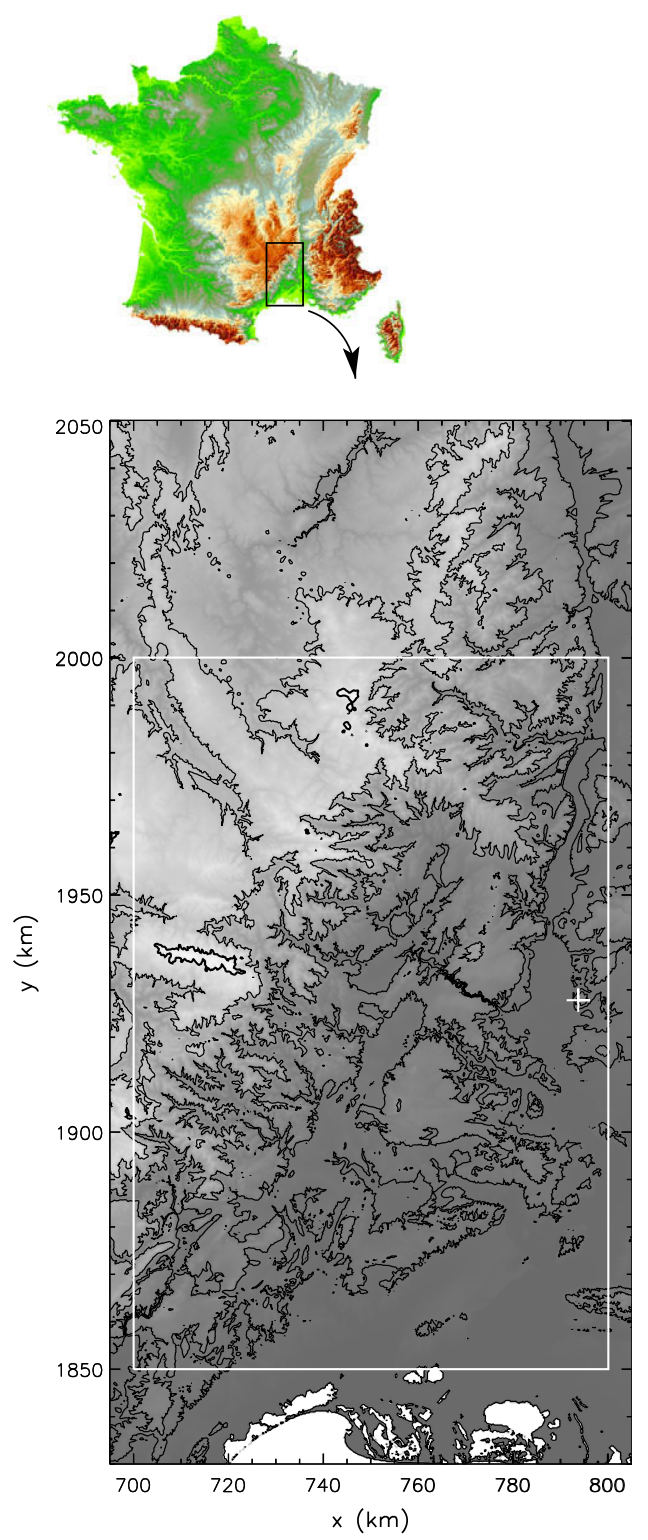

Fig. 1. OHM-CV pilot site and topography. The white lines delineate the study area The white "+" sign marks the location of the radar site at Bollène. The contour lines correspond to altitudes of $0,100,200,500,1000$ and $1500 \mathrm{~m}$. Coordinates are expressed in the extended Lambert II system.

ical of intense precipitation in the Cévennes-Vivarais region: warm and moist air from the Mediterranean sea is lifted up by the topography and rain bands due to shallow convection are formed $[21,22]$. Because convection is initiated on the relief shoulders, rain amounts are larger in the hill/mountain regions than in the plain/ foothill regions (see Fig. 3). Rain rates are lower than for deep convection events, but total rain amounts can be important. For the 20021124 rain event, the maximum rain amount was about 150 $\mathrm{mm}$, with about $6300 \mathrm{~km}^{2}$ over $50 \mathrm{~mm} \mathrm{~h}^{-1}$ and about $1500 \mathrm{~km}^{2}$ over $100 \mathrm{~mm} \mathrm{~h}^{-1}$ (see Fig. 3). This event is less extreme than the 20020908 one, but is nevertheless classified as intense Mediterranean rainfall.

\section{Methodology}

In the present paper, we adopt a geostatistical view of precipitation: the rainfall field is considered as a realization of a random function. The key geostatistical tool for structural analysis is the 


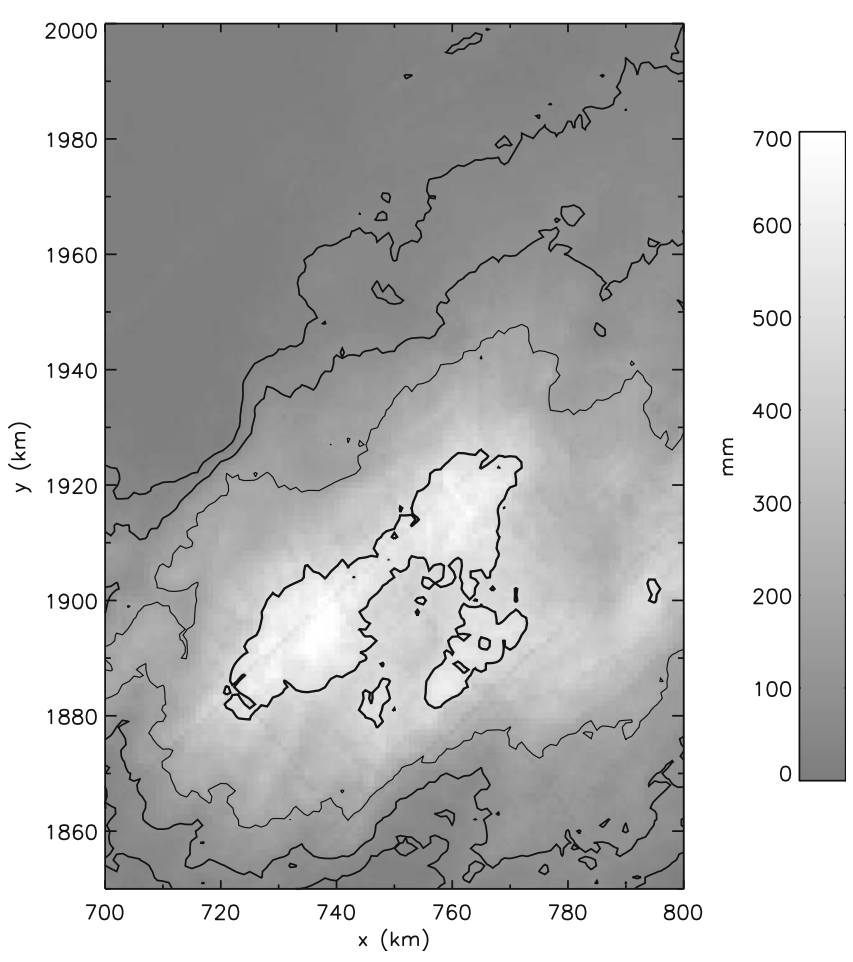

Fig. 2. Total rain amounts in mm over the studied area for the 20020908 rain event. The contour lines correspond to amounts of 50,100, 200 and $500 \mathrm{~mm}$.

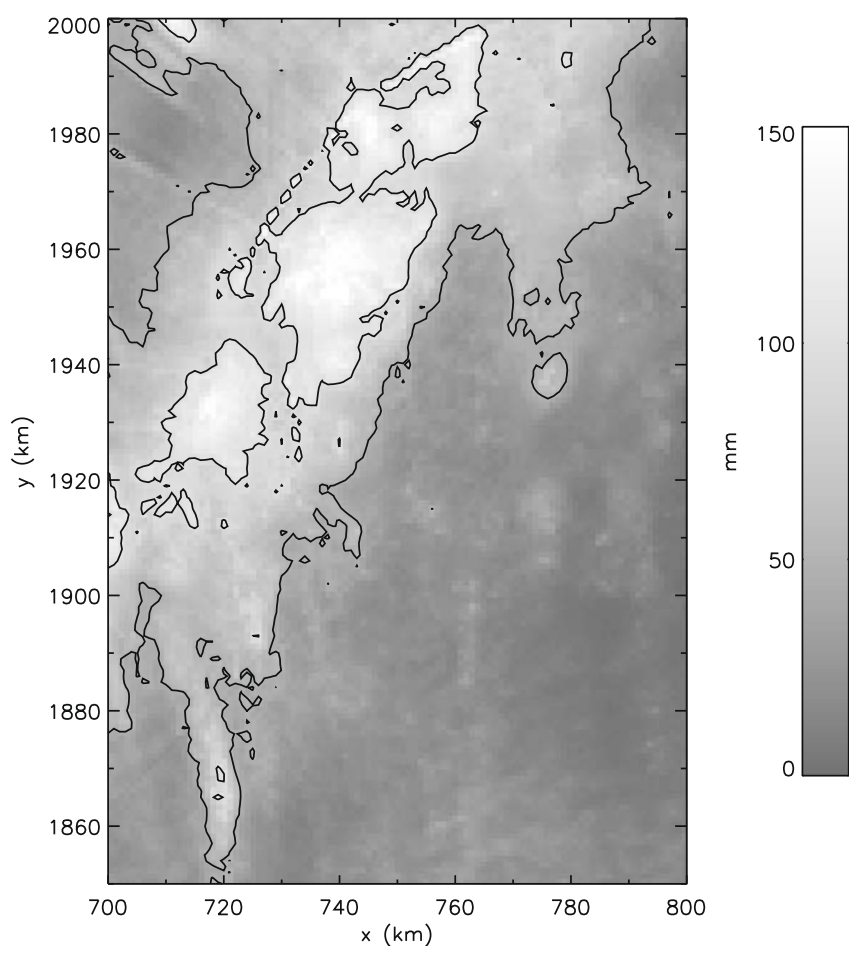

Fig. 3. Total rain in $\mathrm{mm}$ amounts over the studied area for the 20021124 rain event. The contour lines correspond to amounts of 50 and $100 \mathrm{~mm}$. Note that the color scale is different from Fig. 2.

variogram, which quantifies the continuity and the cofluctuation of the data. The variogram is a more general structural tool than the covariance: only intrisic stationarity (i.e., second order stationarity of the increments of the random function) is necessary for the variogram to be defined while second order stationarity is necessary for the covariance to be defined [20]. The application of geostatistical tools for studying precipitation has been first proposed in the early 1980s [12,13] and is still an active domain of research (e.g. [23,24]).

At short accumulation periods, the distribution of rain rates is significantly skewed toward high values and hence far from normality (e.g. $[17,25])$. The indicator approach $[26]$ has been proposed among other reasons to cope with non-Gaussian attributes. In our case, the indicator function $I$ will be 1 if the rain rate $R$ at the considered location $x$ is above a given threshold $t$, and 0 otherwise:

$$
\begin{cases}I(x)=1 & \forall x / R(x) \geqslant t \\ I(x)=0 & \forall x / R(x)<t\end{cases}
$$

The variogram of the indicator function, or indicator variogram, $\gamma_{I}$ is defined as

$\gamma_{I}(h)=\frac{1}{2} E\left\{[I(x+h)-I(x)]^{2}\right\}$

where $h$ denotes the distance lag. The variogram does not depend on the mean of the random function, and hence is more robust than the covariance. It provides useful information about the intermittency (for the considered threshold) as well as about the size and shape of areas above/below the threshold [17,27] and their variability [28]. Thresholded rainfall fields have also been used to investigate their scaling properties in the multi-fractal framework (e.g. [29]).

As mentioned in the introduction, we focus our structural analysis on the characteristic scales and on the anisotropy of rainfall fields. The range of the variogram corresponds to the decorrelation distance: two points distant of more than the range are not correlated on expectation. Hence the range can be seen as a characteristic scale of the studied random function. For precipitation however, the identification of the range (when it exists) of a variogram remains a difficult task because of the complexity of the structure of precipitation fields [15]. Although automatic fitting procedure have been proposed, a choice from the (expert) operator is generally required in the end [20]. As the main objective of this work is to quantify the spatial structure and analyze its variability during an entire rain event at a high resolution in time (a 5-min time step for events lasting about $20 \mathrm{~h}$ ), such a "manual" approach is not tractable.

To quantify the spatial characteristic scale of rain events, we propose instead to use the mean length above the threshold denoted $\bar{l}$. This length corresponds to the average length of the segments defined by rain rate values above the threshold in a given direction. Interestingly, this mean length is not related to the range of the indicator variogram, but rather to the derivative of the indicator variogram at the origin and to the mean proportion of area above the threshold within the studied domain (see [27], Eq. (13))

$\bar{l}_{\theta}=\frac{p_{\theta}}{\left(\frac{\partial \gamma_{l}\left(h_{\theta} \rightarrow 0\right)}{\partial h_{\theta}}\right)}$

where $\bar{l}_{\theta}$ denotes the mean length above the threshold in the direction $\theta, p_{\theta}$ is the proportion of rain rate values above the threshold in the direction $\theta$ and $\gamma_{I}$ is the indicator variogram associated with the threshold. Both $\gamma_{I}$ and $p_{\theta}$ are dimensionless, and both $h$ and $\bar{l}_{\theta}$ are lengths expressed in $\mathrm{km}$. Details about the derivation of Eq. (3) can be found in [27]. Estimating the mean length above the threshold in many directions makes it possible to analyze the anisotropy of rainfall fields.

The mean proportion above a given threshold in a given direction $\theta$ is calculated as the ratio between (1) the sum of the length $l_{i, \theta}$ of the segments defined by rain rate values above the threshold and (2) the sum of the total length $L_{i, \theta}$ of all the $n_{\theta}$ profiles that can be extracted from the domain in the direction $\theta$

$p_{\theta}=\frac{\sum_{i=1}^{n_{\theta}} l_{i, \theta}}{\sum_{i=1}^{n_{\theta}} L_{i, \theta}}$ 


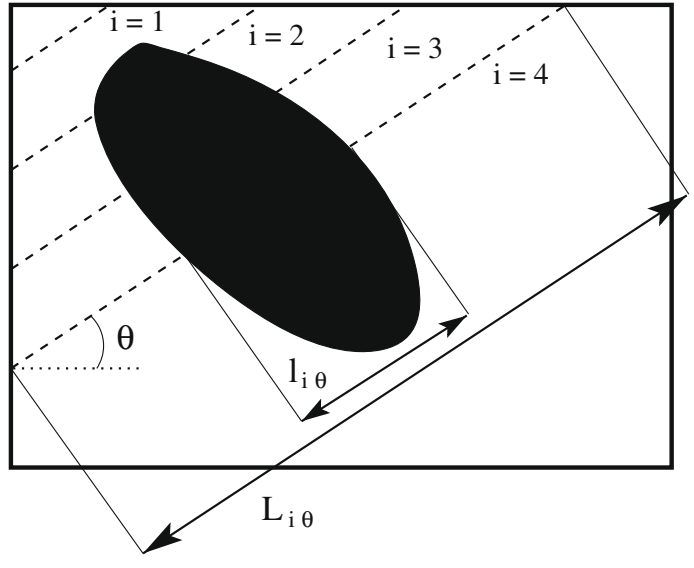

Fig. 4. Definition of $l_{\theta}$ and $L_{\theta}$.

Fig. 4 illustrates the definition of the different terms mentioned above. Similarly to $l_{\theta}$ and $L_{\theta}, \bar{l}_{\theta}$ could be directly computed from the data. However, the indicator variogram provides additional information about the structure and the correlation of the studied random field. Although not used in the present paper, such information is valuable to characterize rainfall fields and will be used in future development of the proposed approach. Hence the indicator variogram $\gamma_{I}$ rather than $\bar{l}_{\theta}$ is directly computed from the data in the present paper. The sample indicator variogram $\gamma_{S I}$ is calculated as

$\gamma_{S I}\left(h_{\theta}\right)=\frac{1}{2 n_{h_{\theta}}} \sum_{i=1}^{n_{h_{\theta}}}\left[I\left(x_{i}+h_{\theta}\right)-I\left(x_{i}\right)\right]^{2}$

where $n_{h_{\theta}}$ denotes the number of pairs of points $\left(x_{i}, x_{i}+h_{\theta}\right)$ in the direction $\theta$ within the domain. Because data points are regularly gridded, distance lags between data points are multiples of the basic grid step in a given direction.

The size of the domain must be adapted to the studied phenomenon. If the domain is too small or not appropriately located to observe the entire precipitating system, the sample variogram and the proportion are not representative of the system at large, and so is not the derived mean length. Our domain is large $\left(100 \times 150 \mathrm{~km}^{2}\right)$ and suited to analyze the two considered rain events (except for a few cases for hourly data). We will assume in the following that sampling effects are negligible in the derived mean length values. Moreover, a proportion above a given threshold close to 0 means that there is no significant rainfall above the threshold within the domain. To avoid taking into account such cases, the mean length is not calculated when the proportion is lower than $1 \%$ (i.e., $150 \mathrm{~km}^{2}$ ).

The variogram must obey some mathematical properties that the sample variogram usually does not. Therefore, it is necessary to fit an allowable variogram model to the sample variogram values. Visual inspection of the 1D sample indicator variograms extracted in many directions suggests that they are linearly increasing for short distance lags. Therefore, the derivative of $\gamma_{I}$ is estimated as the slope of the regression line between the sample indicator variogram values and distance lags from 1 to 7 steps (see Fig. 5). The value of $\gamma_{S I}$ at $h=0$ (which is 0 by definition) is not taken into account in the regression so that possible nugget effect could be considered. As the correlation coefficients are calculated from only seven points, a correction is applied to limit sampling effects [30]. This limit of 7 steps has been chosen as a trade-off between (1) having a large number of points to calculate more reliable correlation coefficients and (2) limiting calculations to sufficiently short distance lags so that the linear model is valid even for short range indicator variograms. The sensitivity of the derived

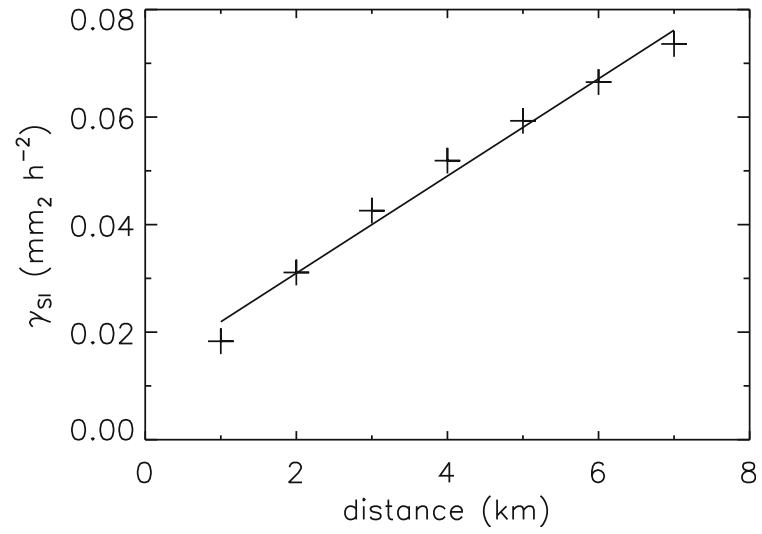

Fig. 5. Example of extracted 1D sample indicator variogram in the direction 0 during the 20020908 rain event at 5 min time resolution for a threshold of $1 \mathrm{~mm} \mathrm{~h}^{-1}$. The "+" signs mark the values of the sample indicator variogram, and the solid line figures the regression line.

fitted parameters to this number has been investigated (not shown here) and appears to be negligible between 6 and 10 steps. Moreover, considering short distance lags to estimate the indicator variogram only requires local stationarity rather than stationarity over the entire domain. The high correlation coefficient values obtained (>0.98 in general) confirm that the supposed linearity between the indicator variogram values and the distance lags is a relevant assumption.

In the previous paragraphs, the way the mean length is estimated in a given direction for a given threshold has been explained. The following paragraphs aim at describing the selection of the directions and thresholds that will be used in the subsequent analysis of the data. Given the fact that the data points are regularly gridded and that the derivative of the indicator variogram is calculated using distance lags up to 7 steps, the directions are simply defined as the angles between the center and the nodes on the edge of a $8 \times 8$-node square, according to Fig. 6 . Hence there are 28 directions for which the indicator variogram will be fitted and the mean length estimated. It is sufficient to have angles between $-90^{\circ}$ and $+90^{\circ}$ because the variogram is symmetrical with respect to the origin.

In order to define the thresholds, we use the quantiles of the distribution of the rain rate values at the pixel scale during each of the two events and for the 4 time resolutions $(5,15,30$ and $60 \mathrm{~min}$ ). Table 1 presents the values of the $10,20,30,50,70,80$ and $90 \%$ quantiles. From these quantiles we have selected two thresholds: $1 \mathrm{~mm} \mathrm{~h}^{-1}$ which corresponds to the precipitating system at large; and $10 \mathrm{~mm} \mathrm{~h}^{-1}$ which corresponds to intense rain

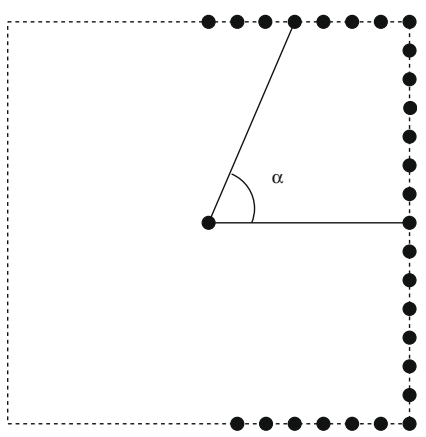

Fig. 6. Scheme explaining how the angle values for the different directions are defined taking advantage of gridded data. The $0^{\circ}$ angle corresponds to the horizontal (West-East orientation). Each filled circle defines one of the 28 directions. 
Table 1

Rain rate quantiles in $\mathrm{mm} \mathrm{h}^{-1}$ for the 20020908 and 20021124 rain events.

\begin{tabular}{lcllllllr}
\hline Event & Time step (min) & $10 \%$ & $20 \%$ & $30 \%$ & $50 \%$ & $70 \%$ & $80 \%$ & $90 \%$ \\
\hline 20020908 & 5 & 0.8 & 1.5 & 2.3 & 4.7 & 9.9 & 18.0 & 39.4 \\
& 15 & 0.4 & 1.0 & 1.3 & 4.1 & 8.9 & 16.4 & 33.6 \\
& 30 & 0.3 & 0.7 & 1.4 & 3.7 & 8.2 & 15.0 & 30.5 \\
& 60 & 0.2 & 0.6 & 1.2 & 3.3 & 7.5 & 13.6 & 28.2 \\
20021124 & 5 & 0.7 & 1.3 & 2.0 & 4.0 & 7.2 & 9.7 & 13.4 \\
& 15 & 0.4 & 0.8 & 1.4 & 3.2 & 6.3 & 8.6 & 12.1 \\
& 30 & 0.3 & 0.7 & 1.2 & 2.9 & 5.7 & 7.9 & 11.0 \\
& 60 & 0.2 & 0.6 & 1.1 & 2.6 & 5.3 & 7.2 & 9.8 \\
\hline
\end{tabular}

cells. The same threshold values are used at the different time resolutions because they correspond to quantiles that are similar from one accumulation period to the other (between $10 \%$ and $30 \%$ for $1 \mathrm{~mm} \mathrm{~h}^{-1}$, and between $70 \%$ and $90 \%$ for $10 \mathrm{~mm} \mathrm{~h}^{-1}$ ). Moreover, it is interesting to note that the quantiles $10-50 \%$ are almost equal for the two rain events, while the quantiles $70 \%, 80 \%$ and $90 \%$ are much larger for the 20020908 rain event. For example, the quantile $90 \%$ at $60 \mathrm{~min}$ resolution is about $30 \mathrm{~mm} \mathrm{~h}^{-1}$ (over the $28 \mathrm{~h}$ this event lasted). This confirms the exceptional aspect of the 20020908 rain event.

\section{Results}

\subsection{Temporal variability of the spatial structure during rain events}

Applying the methodology described in the previous section, the mean length is estimated in 28 directions and for a given threshold for each time step during the two studied rain events. This quantitatively characterizes the spatial structure of rainfall fields. The objective of this section is to analyze the evolution of
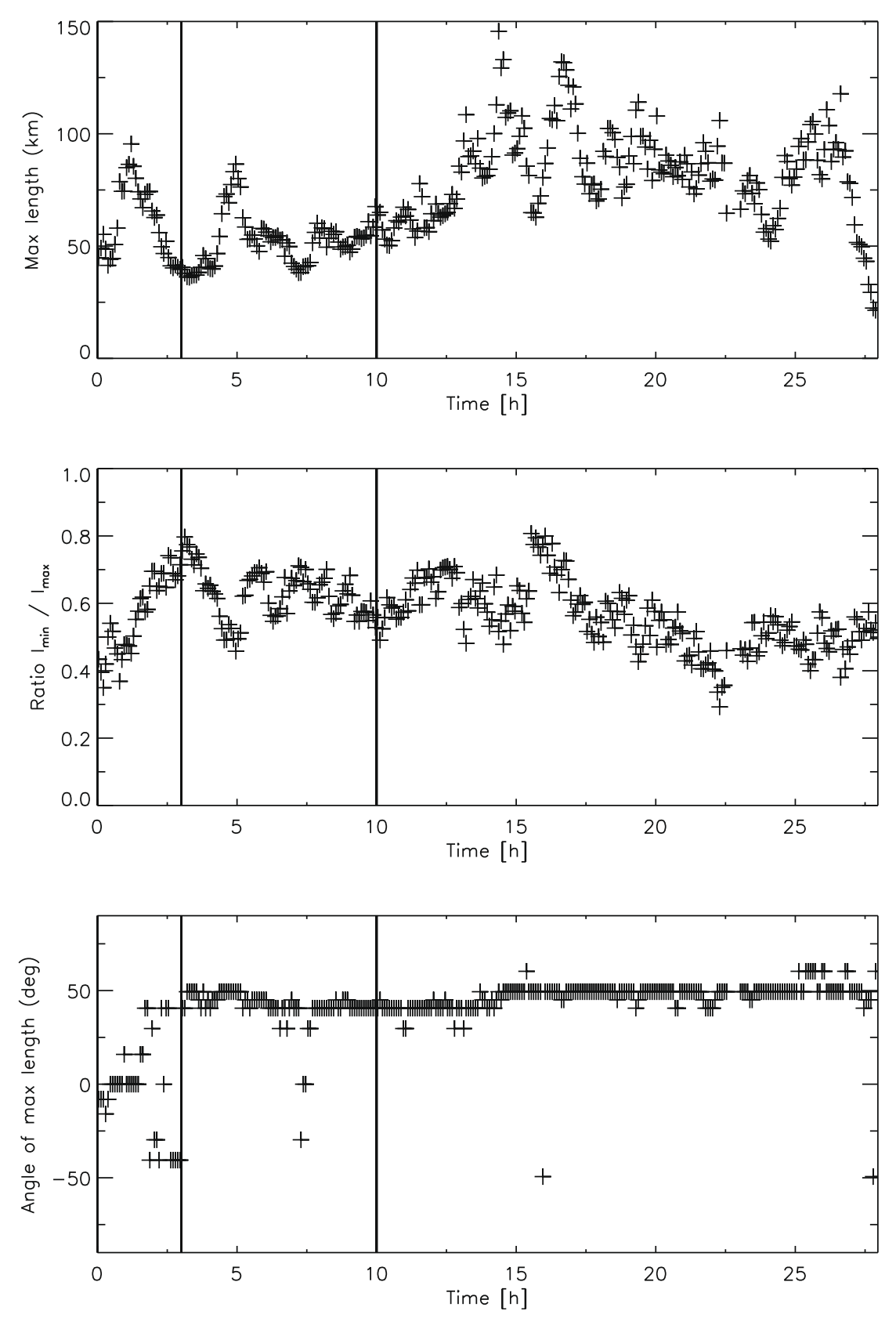

Fig. 7. Max mean length (top), ratio min/max mean length (middle) and direction of max mean length (bottom) as a function of time during the 20020908 rain event, for a threshold of $1 \mathrm{~mm} \mathrm{~h}^{-1}$. The black solid lines delineate the three identified periods (see text). The origin of time is 08:00 UTC on the 8th of September 2002. 
the spatial structure during a rain event and to identify periods with distinct structures due to the dynamics of precipitation. In this section, we focus on the 5-min time resolution, assuming that the structure is less affected by advection at the shortest available accumulation period.

Looking at the structure for individual time steps, the shape of rain cells above the considered threshold is generally elliptic. In order to summarize the large amount of information that is available per time step, the maximum mean length, the ratio between the minimum and maximum mean length (because the shape is elliptic), and the direction (quantified as an angle) of the maximum mean length are computed. They are plotted as a function of time in Fig. $7\left(1 \mathrm{~mm} \mathrm{~h}^{-1}\right.$ threshold $)$ and Fig. $8\left(10 \mathrm{~mm} \mathrm{~h}^{-1}\right.$ threshold) for the 20020908 rain event, and in Figs. $9\left(1 \mathrm{~mm} \mathrm{~h}^{-1}\right.$ threshold) and Fig. $10\left(10 \mathrm{mmh}^{-1}\right.$ threshold $)$ for the 20021124 rain event.
The first feature that must be noted is the existence of peaks in the maximum mean length and in the ratio $\mathrm{min} / \mathrm{max}$ length (top and middle plots in Figs. 7-10) with a period of about $4 \mathrm{~h}$, for both rain events and both thresholds. This is consistent with frequently reported observations of the periodic formation of lines of intense rain cells. Another interesting feature that is general for Figs. 7-10 is the globally strongly negative correlation between the maximum mean length and the ratio minimum/maximum mean length for both rain events and both thresholds. It means that the structure tends to be stretched for large maximum mean lengths and more circular for small maximum mean lengths.

Comparing the structures for the two rain events, it appears that the ratio $\mathrm{min} / \mathrm{max}$ mean length is similar. This indicates that the shape (except for the direction of the maximum mean length) is more or less similar. Concerning the maximum mean length, it is similar for the two rain events for the $1 \mathrm{~mm} \mathrm{~h}^{-1}$ threshold. The
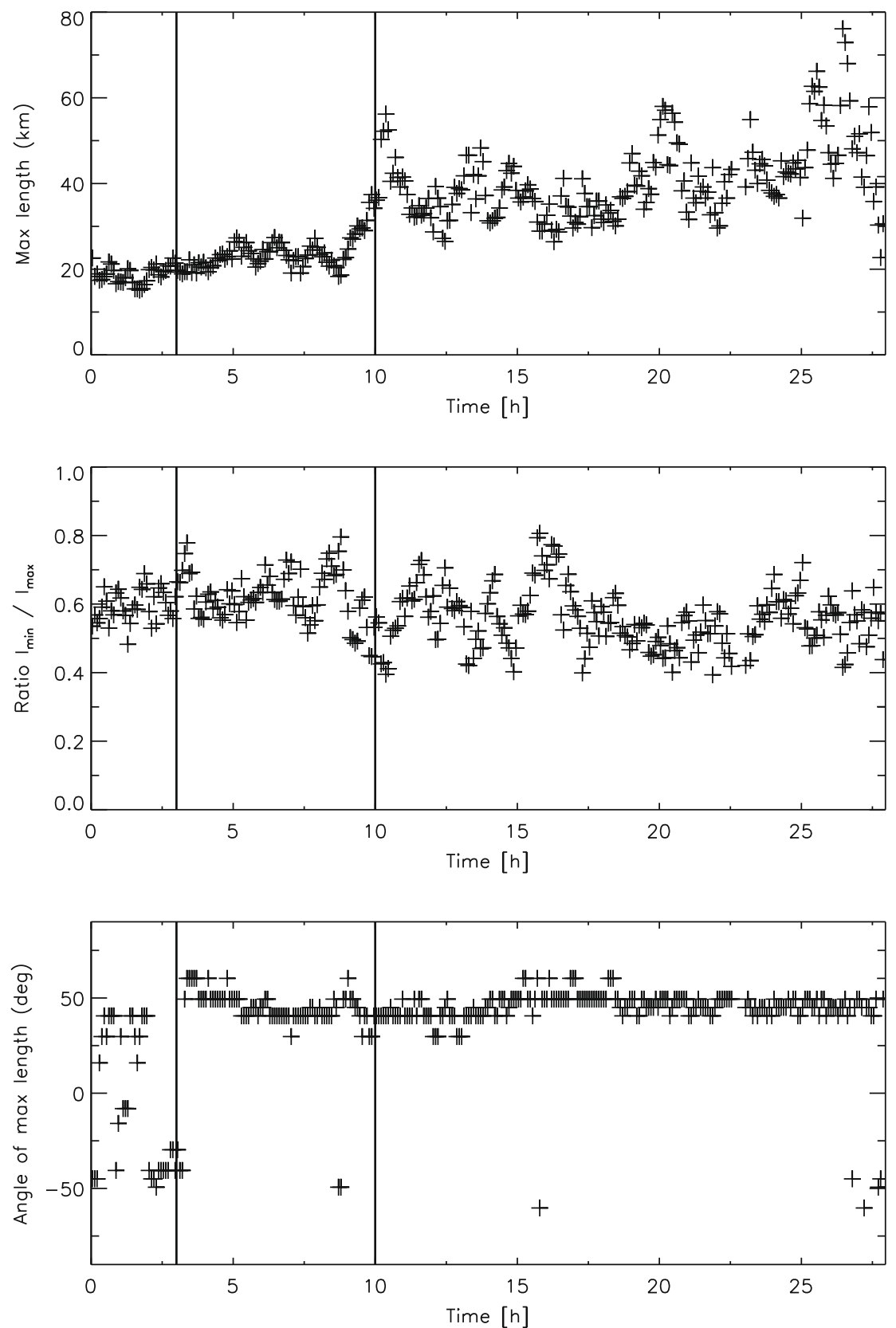

Fig. 8. Same as Fig. 7 for a threshold of $10 \mathrm{~mm} \mathrm{~h}^{-1} \mathrm{~mm} \mathrm{~h}^{-1}$. 

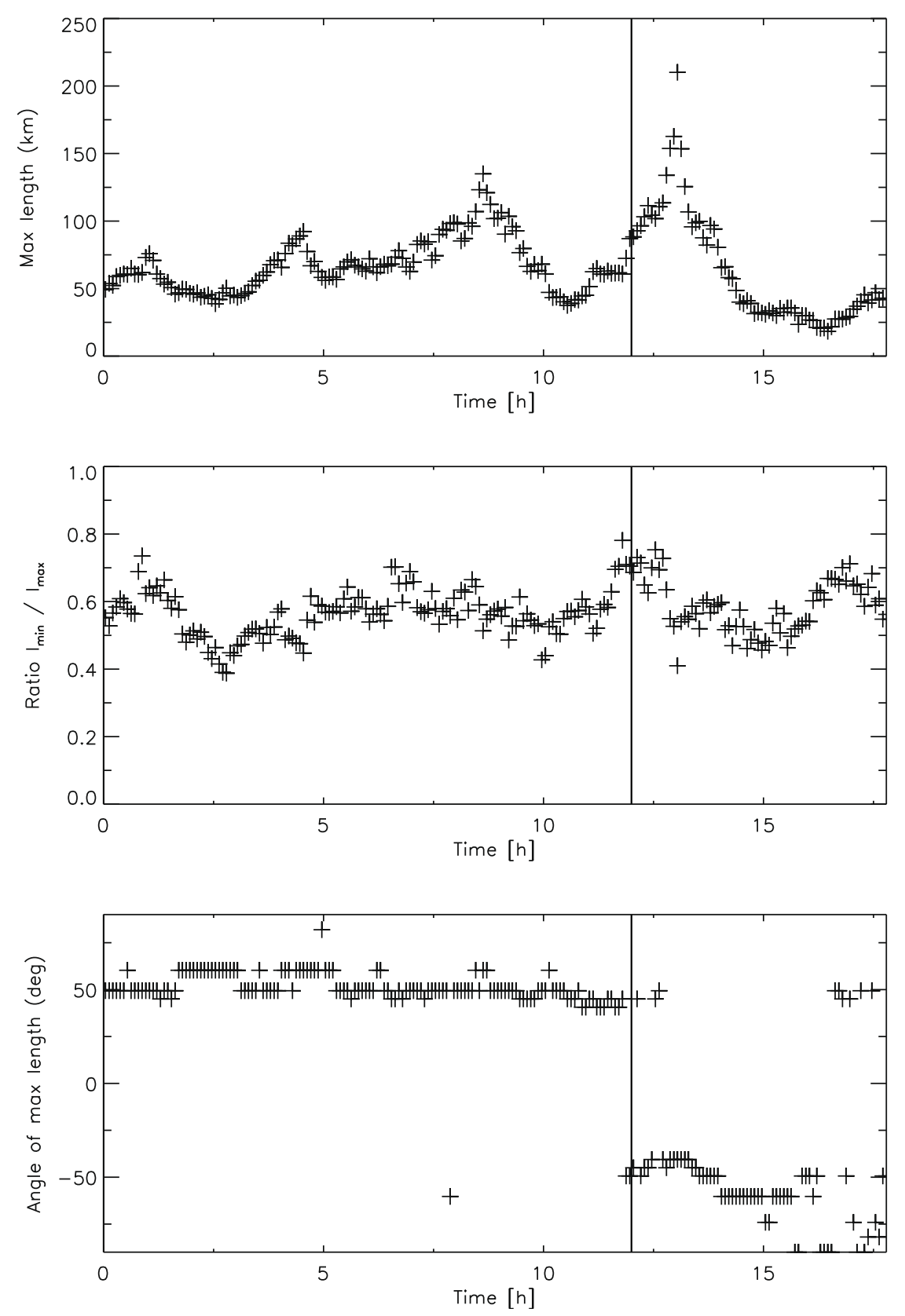

Fig. 9. Max mean length (top), ratio min/max mean length (middle) and direction of max mean length (bottom) as a function of time during the 20021124 rain event, for a threshold of $1 \mathrm{~mm} \mathrm{~h}^{-1}$. The black solid line delineates the two identified periods (see text). The origin of time is 06:00 UTC on the 11th of November 2002.

maximum mean length is even larger for the 20021124 rain event (about $200 \mathrm{~km}$ ) than for the 20020908 rain event (about $150 \mathrm{~km}$ ). However, for the $10 \mathrm{~mm} \mathrm{~h}^{-1}$ threshold, the maximum mean length is much larger on average for the 20020908 rain event than for the 20021124 rain event. This is consistent with the fact that the $70 \%$, $80 \%$ and $90 \%$ quantiles are much larger for the 20020908 rain event than for the 20021124 rain event, confirming that the 20020908 rain event is an exceptional event.

Focusing on the 20020908 rain event, three periods during which the spatial structure is homogeneous can be identified in Figs. 7 and 8.

- There is an abrupt change in the direction of the maximum mean length at $3 \mathrm{~h}$. The direction varies between $-45^{\circ}$ and $+45^{\circ}$ before stabilizing after $3 \mathrm{~h}$ at about $+45^{\circ}$ for the entire event. This change is due to the transition that happened when the convective system above the sea reaches the land (with rugged topography). This transition is visible for both thresholds (1 and $10 \mathrm{~mm} \mathrm{~h}^{-1}$ ). This defines period 1 from 0 to $3 \mathrm{~h}$ (with respect to the beginning of the event at 08 UTC).

- After this first transition period, the structure remains stable with a maximum mean length varying around $60 \mathrm{~km}(23 \mathrm{~km})$, a ratio varying around $0.6(0.6)$ and a direction of maximum mean length at about $+45^{\circ}\left(+45^{\circ}\right)$ for the $1 \mathrm{~mm} \mathrm{~h}^{-1}$ (respectively $10 \mathrm{~mm} \mathrm{~h}^{-1}$ ) threshold. This defines period 2 from 3 to $10 \mathrm{~h}$.

- From 10 to $13 \mathrm{~h}$, the structure is expanding as shown by the increase in both the maximum mean length and the ratio (this period being an exception to the general negative correlation between these two variables). Between 13 and $27 \mathrm{~h}$, the spatial structure remains similar with maximum mean lengths in the order of $80 \mathrm{~km}(40 \mathrm{~km})$, a ratio min/max mean length in the order of $0.5(0.6)$, and a direction of about $+50^{\circ}\left(+45^{\circ}\right)$ for the 

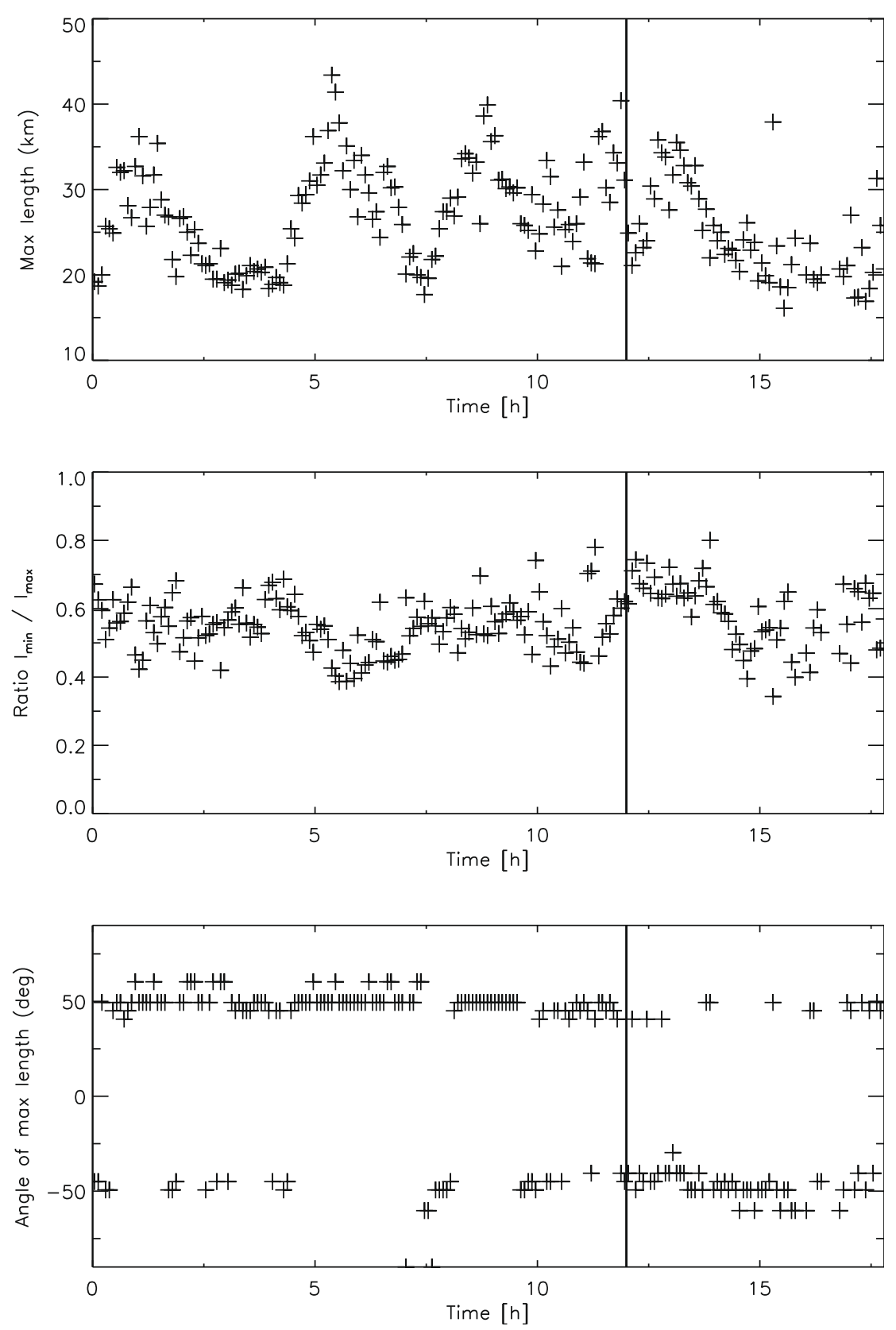

Fig. 10. Same as Fig. 9 for a threshold of $10 \mathrm{~mm} \mathrm{~h}^{-1}$.

$1 \mathrm{~mm} \mathrm{~h}^{-1}$ (respectively $10 \mathrm{~mm} \mathrm{~h}^{-1}$ ) threshold. Between 27 and $28 \mathrm{~h}$, the eastward cold front crosses the study area and moves out the MCS, as indicated by the abrupt decrease in the maximum mean length. This defines period 3 from 10 to $28 \mathrm{~h}$. It can be noted that on average the structure is more stretched for period 3 than for period 2 .

These three periods do not exactly correspond to the phases identified in D05 because in the present work the focus is on the spatial structure while it is on the meteorological features in D05. Nevertheless, the three periods can be related to the three phases described in D05. Periods 1 and 2 together correspond to phase 1 in D05. Phases 2 and 3 in D05 correspond to period 3. The displacement of the MCS due to the eastward cold front (phase 3 in D05) does not have a significant signature in terms of spatial structure, except when the MCS is pushed out of the study area (around $27 \mathrm{~h}$ ).
To illustrate the variability of the spatial structure between the three periods identified during the 20020908 rain event, Figs. 11 and 12 present the indicator function and the spatial structure (quantified by the mean length above the threshold in all the directions) for a particular time step within each of the three periods for both thresholds. For the three examples, there is a very good agreement between the structure as seen by eye when looking at the indicator and the structure quantified by the mean length. It must be noted that the mean length obviously tends to smooth the shape and size of the rain cells. This is due in particular to the fact that the mean length (as we estimate it) in a given fixed direction cannot capture the curved shapes of rain cells and hence leads to smaller scales.

Focusing on the 20021124 rain event, Figs. 9 and 10 clearly show two periods within the event. These two periods exhibit similar maximum mean length and ratio values but they strongly differ in the direction of the maximum mean length. There is an 

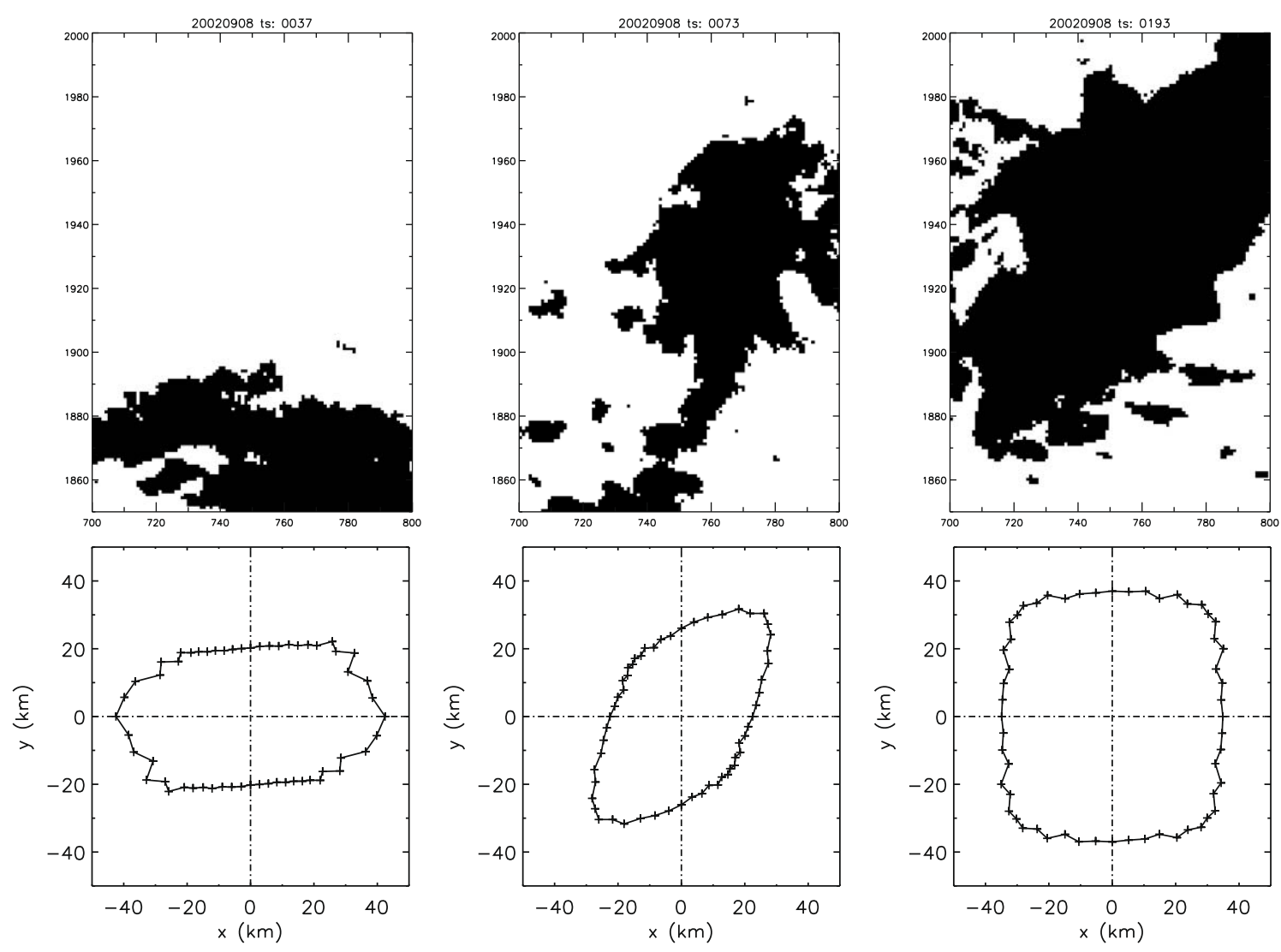

Fig. 11. Examples of rain rate fields observed during period 1 (left), 2 (center) and 3 (right), with black regions indicating the values above the threshold (top) and the corresponding spatial structure quantified by the mean length above the threshold in all directions (bottom) during the 20020908 rain event, for a threshold of 1 mm $\mathrm{h}^{-1}$ and a time resolution of $5 \mathrm{~min}$.

abrupt change at about $12 \mathrm{~h}$, the direction of maximum mean length going from about $+50^{\circ}$ to about $-50^{\circ}$. This shift is related to a change in the dominant wind direction during the rain event and defines the two periods:

- Period 1: from 0 to $12 \mathrm{~h}$, corresponding to a direction of maximum length of about $+50^{\circ}$.

- Period 2: from 12 to $18 \mathrm{~h}$, corresponding to a direction of maximum length of about $-50^{\circ}$.

For both periods, the maximum mean length is about $75 \mathrm{~km}$ $(28 \mathrm{~km})$ and the ratio is about $0.6(0.6)$ for the $1 \mathrm{~mm} \mathrm{~h}^{-1}$ $\left(10 \mathrm{~mm} \mathrm{~h}^{-1}\right.$, respectively) threshold. To limit the length of the present paper, the indicator and structure plots corresponding to particular time steps for the two periods (as in Figs. 11and 12) are not displayed but the agreement is similar to what has been noted for the 20020908 rain event.

\subsection{Influence of time resolution}

In this section, the objective is to investigate the influence of the time resolution of rain rate measurements on the spatial structure. This is particularly relevant to investigate the hydrological response of catchments of different sizes in order to identify the critical scale at which the resulting discharge will be the largest and could potentially generate flash floods.

Figs. 13 and 14 show the mean spatial structure estimated at an increasing accumulation period of 5, 15, 30 and $60 \mathrm{~min}$, for the 3 periods of the 20020908 rain event for both thresholds. For all periods, the structure is stretched when the time step increases. The direction of the apparent motion of the rain field corresponds to the dominant wind and this motion is limited in the direction perpendicular to the wind direction. Hence this extension of the spatial structure is mainly due to the advection of rain cells by the wind. It is worth noting that the direction of advection by the dominant wind can be different from the direction of the maximum mean length in the field at a higher accumulation period. In such case, the spatial structure is very different at short and long time steps. This is illustrated in the left panel of Figs. 13 and 14 when comparing the structure at 5 and $60 \mathrm{~min}$ time resolution.

Similarly, Figs. 15 and 16 show the mean spatial structure for the 2 periods of the 20021124 rain event for both thresholds. The difference in the direction of maximum mean length is clear between the 2 periods for both thresholds and all time resolutions. Again, this is related to the change in the direction of the dominant wind during the rain event. The sizes are similar for both periods except for the 60-min time resolution. The large mean length values at this time resolution for period 1 are due to a few time steps during which the domain is almost entirely above the $1 \mathrm{~mm} \mathrm{~h}^{-1}$ threshold. Hence these large values are uncertain and not representative of the system at large (see Section 3). For the $1 \mathrm{~mm} \mathrm{~h}^{-1}$ threshold and contrary to the 20020908 rain event, the extension in the mean length is not limited to the direction of the dominant wind. It is larger in the dominant wind direction, but it is significant in all directions. In this context of orographic rainfall, rain cells are generated over a line of spurs oriented at about $60^{\circ}$ (see Fig. 1) which are not aligned with the dominant wind direction. Hence increasing the accumulation period tends to merge these different rain cells. Therefore, the mean spatial structure does not only increase in the advection direction. As indicated by the more isotropic features of the spatial structure for period 2, this effect is stronger during period 2 because the dominant wind direction is 

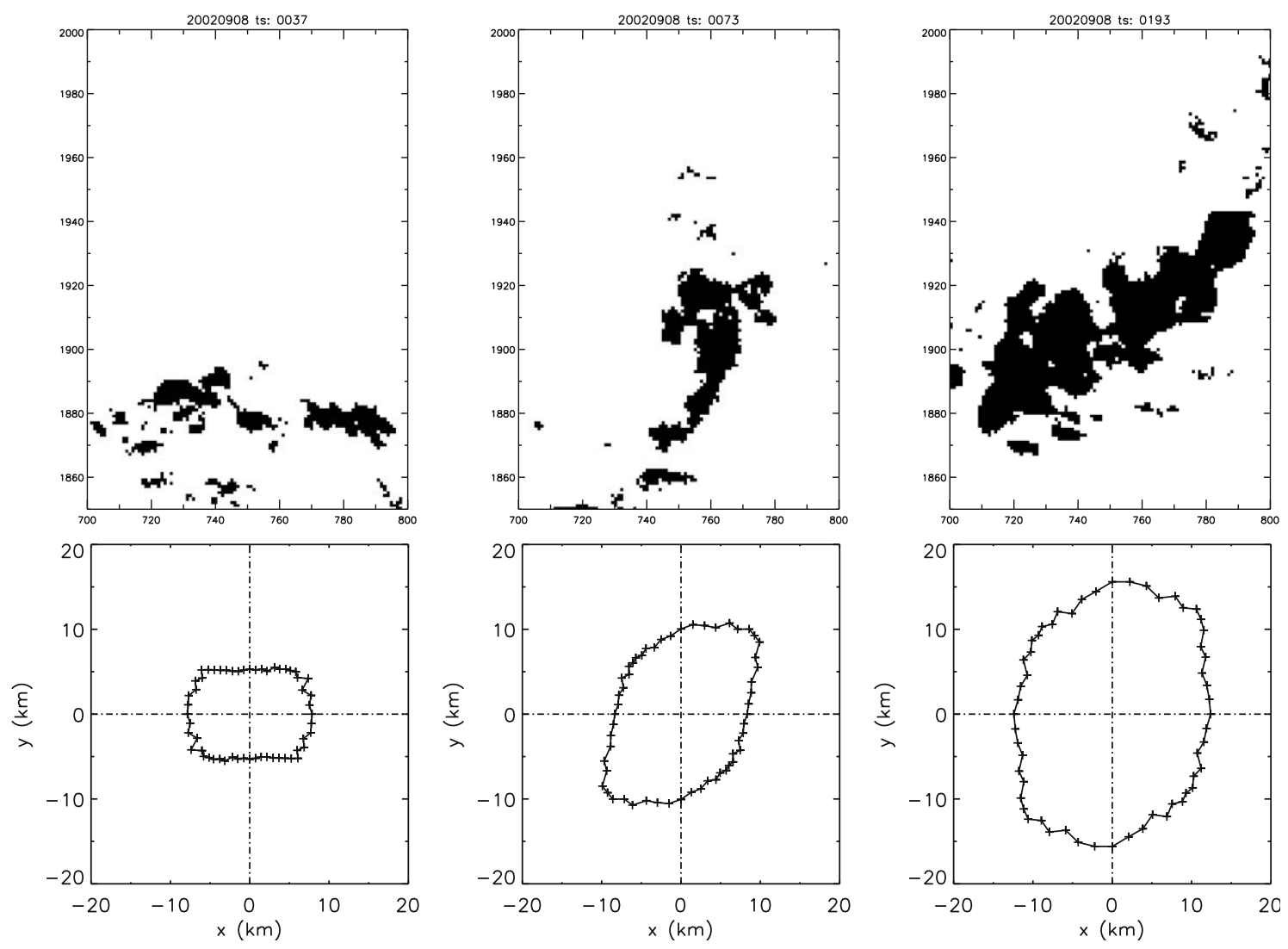

Fig. 12. Same as Fig. 11 for a threshold of $10 \mathrm{~mm} \mathrm{~h}^{-1}$. Please note the change of scale for the spatial structure.
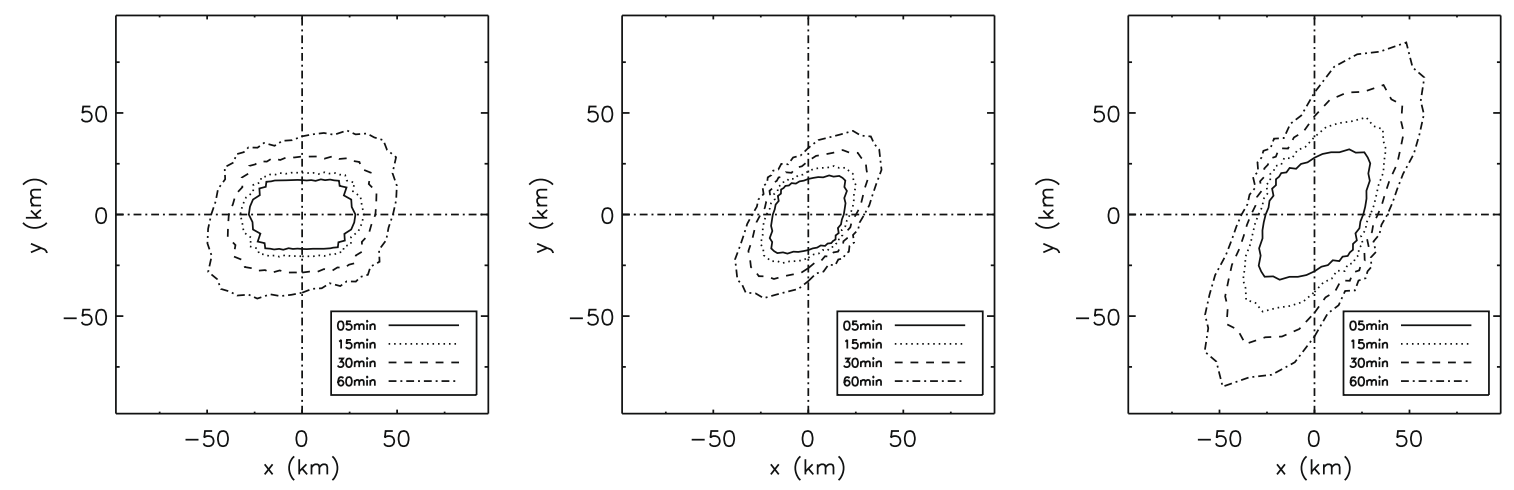

Fig. 13. Mean spatial structure of period 1 (left), 2 (center) and 3 (right) during the 20020908 event for a time resolution of $5,15,30$ and 60 min, for a threshold of $1 \mathrm{~mm} \mathrm{~h}^{-1}$.
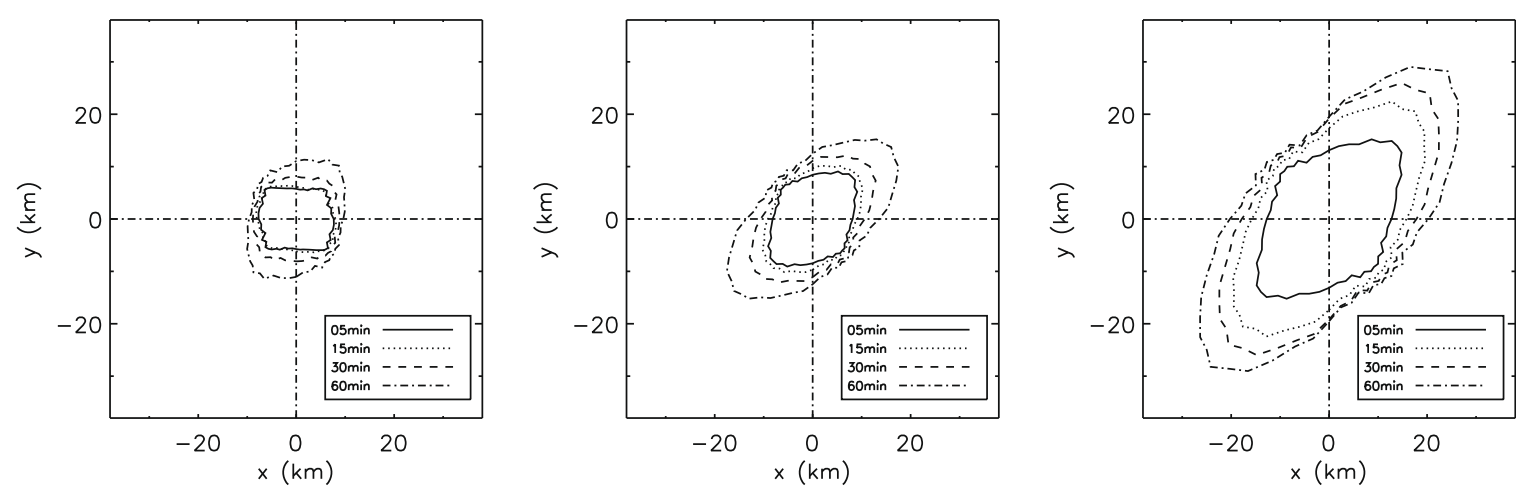

Fig. 14. Same as Fig. 13 for a threshold of $10 \mathrm{~mm} \mathrm{~h}^{-1}$. Please note the change of scale. 

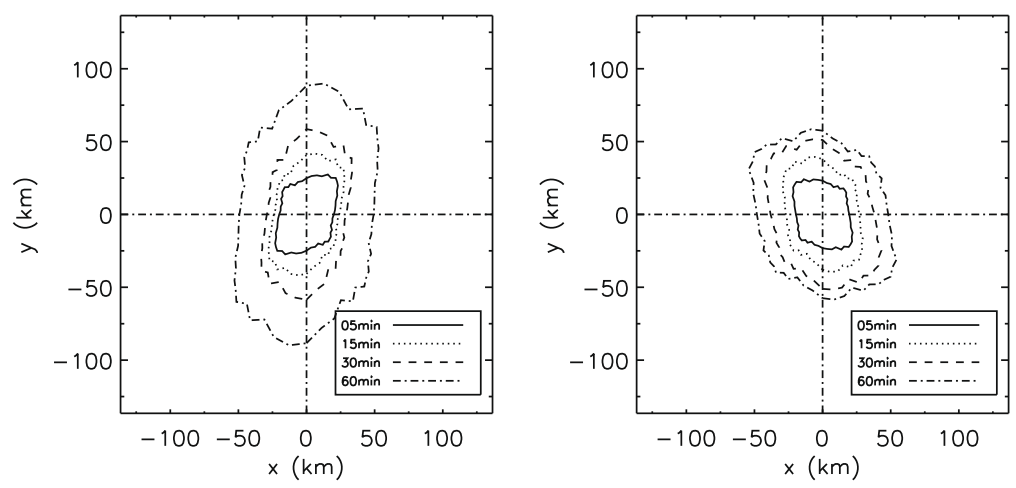

Fig. 15. Mean spatial structure of rainfall of period 1 (left) and 2 (right) during the 20021124 rain event for a time resolution of 5 , 15 , 30 and 60 min, for a threshold of $1 \mathrm{~mm} \mathrm{~h}^{-1}$.
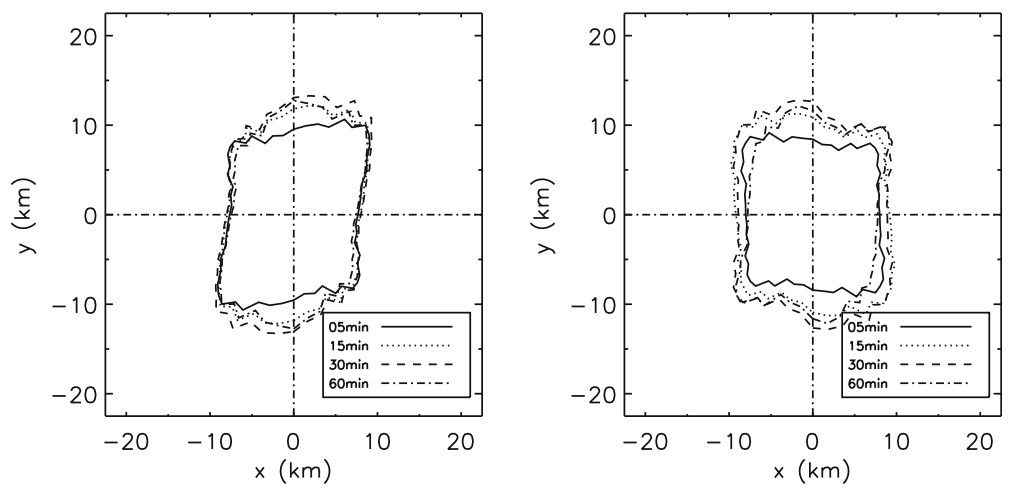

Fig. 16. Same as Fig. 15 for a threshold of $10 \mathrm{~mm} \mathrm{~h}^{-1}$. Please note the change of scale.

more perpendicular to the line of spurs than during period 1 . For the $10 \mathrm{~mm} \mathrm{~h}^{-1}$ threshold, there is no significant extension of the spatial structure when the accumulation period increases. Shallow convection does not produce very intense and long lasting rain cells. Advection is then compensated by the decrease in rain rate due to time averaging and therefore the spatial structure does not extend.

Compared to the mean structures of the 20020908 rain event, the mean structures of the 20021124 rain event exhibit smaller sizes for the $10 \mathrm{~mm} \mathrm{~h}^{-1}$ threshold. This is consistent with the fact that the 20021124 event is a typical "cévenol" event, during which shallow convection is triggered by topography (e.g. [21]) and remains limited. On the contrary, the 20020908 event is a stationary mesoscale convective system, with a different dynamics based in particular on the formation of a pool of cold air in the plain/foothill region. This cold pool results in stationary and long lasting convection. This explains the significant extension of the structure of intense rain cells even at 60 min time resolution for the 20020908 rain event.

\section{Conclusions}

The structure of intense precipitation, and in particular the characteristic scale and the anisotropy, is of primary importance for a better understanding, modeling and forecasting of intense rainfall events and resulting flash floods. In this paper, we analyze the variability of the spatial structure during intense Mediterranean precipitation.

We focus on two intense rain events that occured on the 8-9 September 2002 and on the 11 November 2002. The 20020908 rain event was a mesoscale convective system with convective cells consistently appearing at stationary locations. This resulted in huge total rain amounts over an extended area. The 20021124 rain event was more typical of the regional climatology, characterized by shallow convection triggered by topography. Total rain amounts were less extreme but still significant. High space-time resolution $\left(1 \times 1 \mathrm{~km}^{2}\right.$ every $\left.5 \mathrm{~min}\right)$ rain rate data were collected from an operational weather radar and a dense network of rain gauges. From the analysis of the quantiles of rain rate, two thresholds were determined: $1 \mathrm{~mm} \mathrm{~h}^{-1}$ to characterize the precipitating system at large, and $10 \mathrm{~mm} \mathrm{~h}^{-1}$ to characterize intense rain cells.

The variogram is a useful geostatistical tool to investigate the structure of precipitation. Using the indicator variogram, the mean length above the two thresholds is estimated. Analyzing the mean length in many directions during the studied rain events, the characteristic scale and the anisotropy have been quantified, as well as their variability during intense Mediterranean rainfall events.

First it is possible to identify within an intense rain event distinct periods during which the spatial structure is homogeneous. These periods are related to the dynamics of the rain event. Second, the spatial structure of intense rainfall exhibits on average a more or less elliptic shape. For the $1 \mathrm{~mm} \mathrm{~h}^{-1}$ threshold, the two studied rain events are found to have a similar spatial structure in terms of typical size and shape. For the $10 \mathrm{~mm} \mathrm{~h}^{-1}$ threshold, the spatial structure is clearly larger for the 20020908 rain event, reflecting the different dynamics and processes in these two types of intense Mediterranean rain event. Third, the effect of time integration on the spatial structure has been investigated. The increase of the time step results in the stretching of the spatial structure of intense rain cells because of advection. The effect of advection is enhanced 
for strong convective events as illustrated by the 20020908 rain event, or inhibited for shallow convection events as illustrated by the 20021124 rain event.

The approach proposed in this paper has been shown to be an efficient tool to analyze the variability of the structure of precipitation and to partition rain events in homogeneous periods during which the mean structure can be considered as representative. The quantification of the spatial structure of rainfall and its evolution with time resolution is an information of primary importance for the evaluation of the rainfall fields simulated by numerical weather models as well as for the identification of the spatial characteristics of the basins that will have the strongest hydrological response to the considered type of rain events. In the near future, this approach will be applied to a larger set of intense rain events in the same region in order to establish reliable statistics on the typical spatial structure of intense Mediterranean precipitation. It must be noted that this methodology can also be applied in different climatic regions, by simply adapting the threshold values to the local climatology of rain rates.

\section{Acknowledgements}

The authors acknowledge the financial support from the French Project CYPRIM and the EU Project FLOODsite (GOCE-CT-2004505420).

\section{References}

[1] Duclos P, Vidonne O, Beuf P, Perray P, Stoebner A. Flash flood disaster: Nîmes, France, 1988. Eur J Epidemiol 1991;7(4):365-71.

[2] Senesi S, Bougeault P, Chèze J-L, Cosentino P, Thepenier R-M. The Vaison-laRomaine flash flood: mesoscale analysis and predictability issues. Weathe Forecast 1996;11(4):417-42.

[3] Gaume E, Livet M, Desbordes M, Villeuneuve J-P. Hydrological analysis of the river Aude France flash flood on 12 and 13 November 1999. J Hydrol 2004;286(1-4):135-54.

[4] Delrieu G, Ducrocq V, Gaume E, Nicol J, Payrastre O, Yates E, et al. The catastrophic flash-flood event of 8-9 September 2002 in the Gard region, France: a first case study for the Cévennes-Vivarais Mediterranean Hydrometeorological Observatory. J Hydrometeor 2005;6(1):34-52.

[5] Le Lay M, Saulnier G-M. Exploring the signature of climate and landscape spatial variabilities in flash flood events: Case of the 8-9 September 2002 Cévennes-Vivarais catastrophic event. Geophys Res Lett 2007;34:L13401.

[6] Chancibault K, Anquetin S, Ducrocq V, Saulnier G-M. Hydrological evaluation of high-resolution precipitation forecasts of the Gard flash-flood event (8-9 September 2002). Q J Roy Meteor Soc 2007;132(617):1091-117.
[7] Austin PM, Houze RAJ. Analysis of the structure of precipitation patterns in New England. J Appl Meteor 1972;11(6):926-35.

[8] Hobbs PV, Matejka TJ, Herzegh PH, Locatelli JD, Houze RAJ. The mesoscale and microscale structure and organization of clouds and precipitation in midlatitude cyclones. I: a case study of a cold front. J Atmos Sci 1980;37(3):568-96.

[9] Crane RK. Space-time structure of rain rate fields. J Geophys Res 1990;95(D3):2011-20.

[10] Steiner M, Houze RAJ, Yuter SE. Climatological characterization of threedimensional storm structure from operational radar and rain gauge data. Appl Meteor 1995;34(9):1978-2007.

[11] Berg W, Kummerow C, Morales CA. Differences between East and West Pacific rainfall systems. J Climate 2002;15(24):3659-72.

[12] Delhomme J-P. Kriging in the hydrosciences. Adv Water Resour 1978;1(5):251-66.

[13] Creutin J-D, Obled C. Objective analyses and mapping techniques for rainfall fields: an objective comparison. Water Resour Res 1982;18(2):413-31.

[14] Lebel T, Bastin G, Obled C, Creutin J-D. On the accuracy of areal rainfall estimation: a case study. Water Resour Res 1987;23(11):2123-34.

[15] Bacchi B, Kottegoda NT. Identification and calibration of spatial correlation patterns of rainfall. J Hydrol 1995;165(1-4):311-48.

[16] Goovaerts P. Geostatistical approaches for incorporating elevation into the spatial interpolation of rainfall. J Hydrol 2000;228(1-2):113-29.

[17] Barancourt C, Creutin J-D, Rivoirard J. A method for delineating and estimating rainfall fields. Water Resour Res 1992;28(4):1133-44.

[18] Germann U, Joss J. Variograms of radar reflectivity to describe the spatial continuity of Alpine precipitation. J Appl Meteor 2001;40(6):1042-59.

[19] Berne A, Delrieu G, Creutin J-D, Obled C. Temporal and spatial resolution of rainfall measurements required for urban hydrology. J Hydrol 2004;299(34):166-79.

[20] Chilès J-P, Delfiner P. Geostatistics: Modeling spatial uncertainty. Probability and statistics. Wiley; 1999.

[21] Miniscloux F, Creutin J-D, Anquetin S. Geostatistical analysis of orographic rain bands. J Appl Meteor 2001;40(11):1835-54.

[22] Anquetin S, Miniscloux F, Creutin J-D. Numerical simulation of orographic rainbands. J Geophys Res 2003;108(D8):8386.

[23] Campling P, Gobin A, Feyen J. Temporal and spatial rainfall analysis across a humid tropical catchment. Hydrol Processes 2001;15(3):359-75.

[24] Skøien JO, Blöschl G. Catchments as space-time filters a joint spatio-tempora geostatistical analysis of runoff and precipitation. Hydrol Earth Syst Sci 2006;10:645-62

[25] Habib E, Krajewski WF, Ciach GJ. Estimation of rainfall interstation correlation. J Hydrometeor 2001;2(6):621-9.

[26] Journel AG. Non parametric estimation of spatial distributions. Math Geology 1983;15(3):445-67.

[27] Carle SF, Fogg GE. Transition probability-based indicator geostatistics. Math Geology 1996;4(4):453-76.

[28] Ritzi RWJ. Behavior of indicator variograms and transition probabilities in relation to the variance in lengths of hydrofacies. Water Resour Res 2000;36(11):3375-81.

[29] Lovejoy S, Schertzer D, Tsonis AA. Functional box-counting and multiple elliptic dimensions in rain. Science 1987;235(4792):1036-8.

[30] Pearson K. On the correction necessary for the correlation ratio. Biometrika 1923;14(3/4):412-7. 